ORNL-3059

Contract No. W-7405-eng-26

METAIIURGY DIVISION

DEVELOPMENT OF NONDESTRUCTIVE TESTS FOR THE EXPERTMENTAI

GAS-COOLED REACTOR FUEI, ELEMENI

R. W. McClung and R. A. Nance

DATE ISSUED

MAR 2- 1961

OAK RIDGE NATIONAL IABORATORY

Oak Ridge, Tennessee

operated by

UNION CARBIDE CORPORATION

for the

U. S. ATOMIC ENERGY COMMISSION 


\section{DISCLAIMER}

This report was prepared as an account of work sponsored by an agency of the United States Government. Neither the United States Government nor any agency Thereof, nor any of their employees, makes any warranty, express or implied, or assumes any legal liability or responsibility for the accuracy, completeness, or usefulness of any information, apparatus, product, or process disclosed, or represents that its use would not infringe privately owned rights. Reference herein to any specific commercial product, process, or service by trade name, trademark, manufacturer, or otherwise does not necessarily constitute or imply its endorsement, recommendation, or favoring by the United States Government or any agency thereof. The views and opinions of authors expressed herein do not necessarily state or reflect those of the United States Government or any agency thereof. 


\section{DISCLAIMER}

Portions of this document may be illegible in electronic image products. Images are produced from the best available original document. 


\section{DEVELOPMENT OF NONDESTRUCTIVE TESTS FOR THE EXPERIMENTAL} GAS-COOLED REACTOR FUEL ELEMENT

R. W. McClung and R. A. Nance

\section{ABSTRACT}

The Title I design fuel assembly and each of its components for the Experimental Gas-Cooled Reactor (EGCR) are described. The development of the specific nondestructive testing techniques for the evaluation of the components and the fabricated fuel capsule is presented. These techniques include penetrants, pulse-echo and resonance ultrasonics, radiography, eddy-currents, helium leak testing, and others. Discussion is made on the capabilities and limitations of these techniques for the specific inspection problems and reasons presented for the selection of the inspection requirements.

\section{INTRODUCTION}

The Nondestructive Test Development (NDT) Group has been developing the nondestructive inspection techniques which will be recommended for use on the EGCR fuel element and its component parts. Figure 1 is an exploded view of the EGCR Title I design fuel assembly. It consists of seven rodtype fuel capsules symmetrically arranged in a graphite support sleeve by means of top and bottom spiders. Basically, each of the fuel capsules consists of a stack of $\mathrm{UO}_{2}$ pellets encapsulated in a 0.710 -in.-0.d. $\mathrm{x}$ 0.020-in.-wall type 304 stainless steel tube. other component parts for the fuel capsule proper are a midplane spacer to maintain proper separation between the respective capsules and the graphite sleeve, end caps for the welded closure of the capsule, and $\mathrm{MgO}$ pellets which separate the $\mathrm{UO}_{2}$ pellets from the end caps. Figure 2 permits a better view of the individual parts. The recent pilot plant program for the assembly of fifty Title I fuel elements ${ }^{1}$

\footnotetext{
IE. A. Wick and R. I. Heestand, Manufacture of Fifty Prototype Fuel Elements for the EGCR, ORNL-2936 (Dec. 12, 1960).
} 


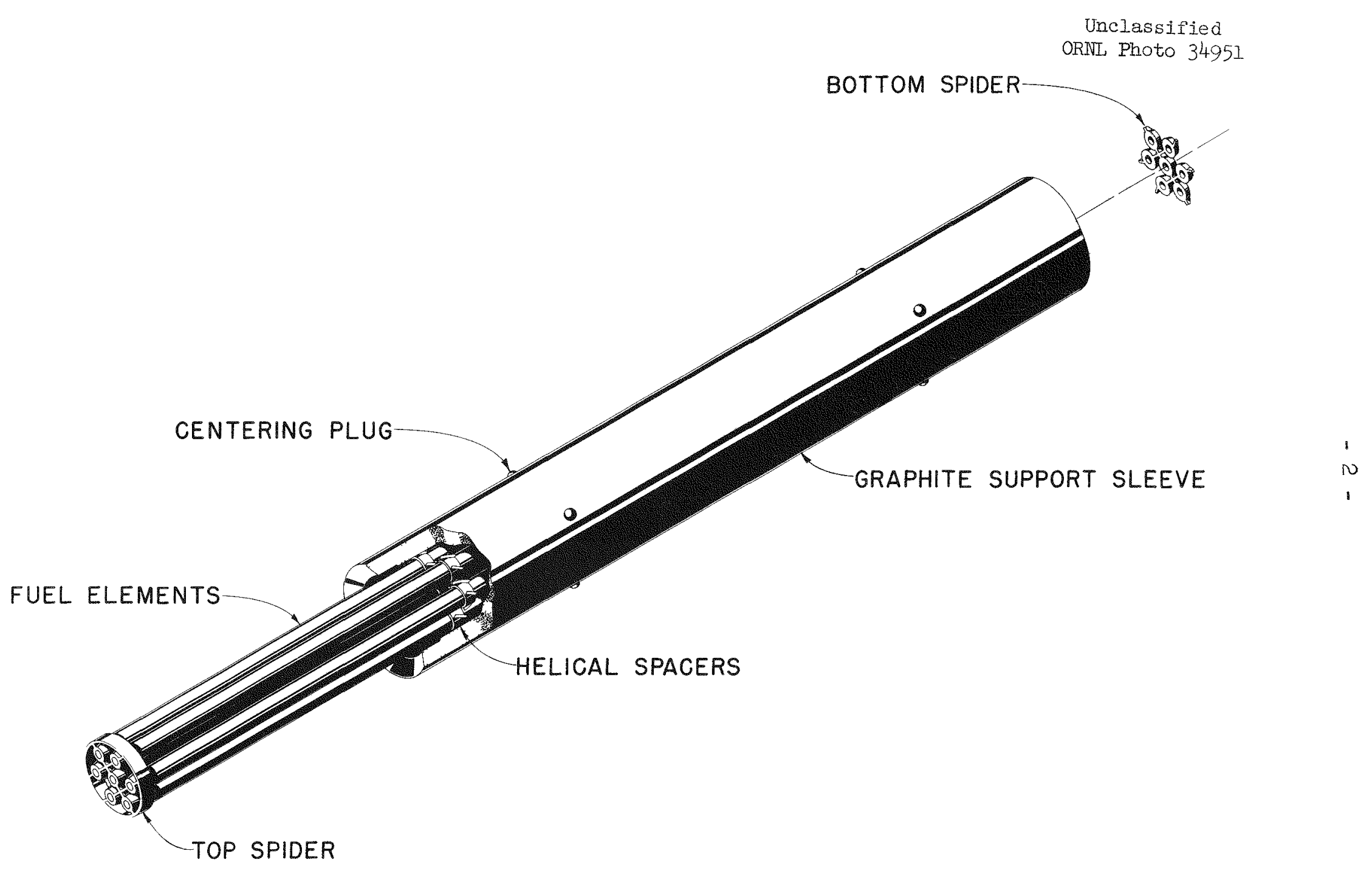

Fig. I Title I Design Fuel Assembly for EGCR. 
$+.0 \quad . \quad .$.

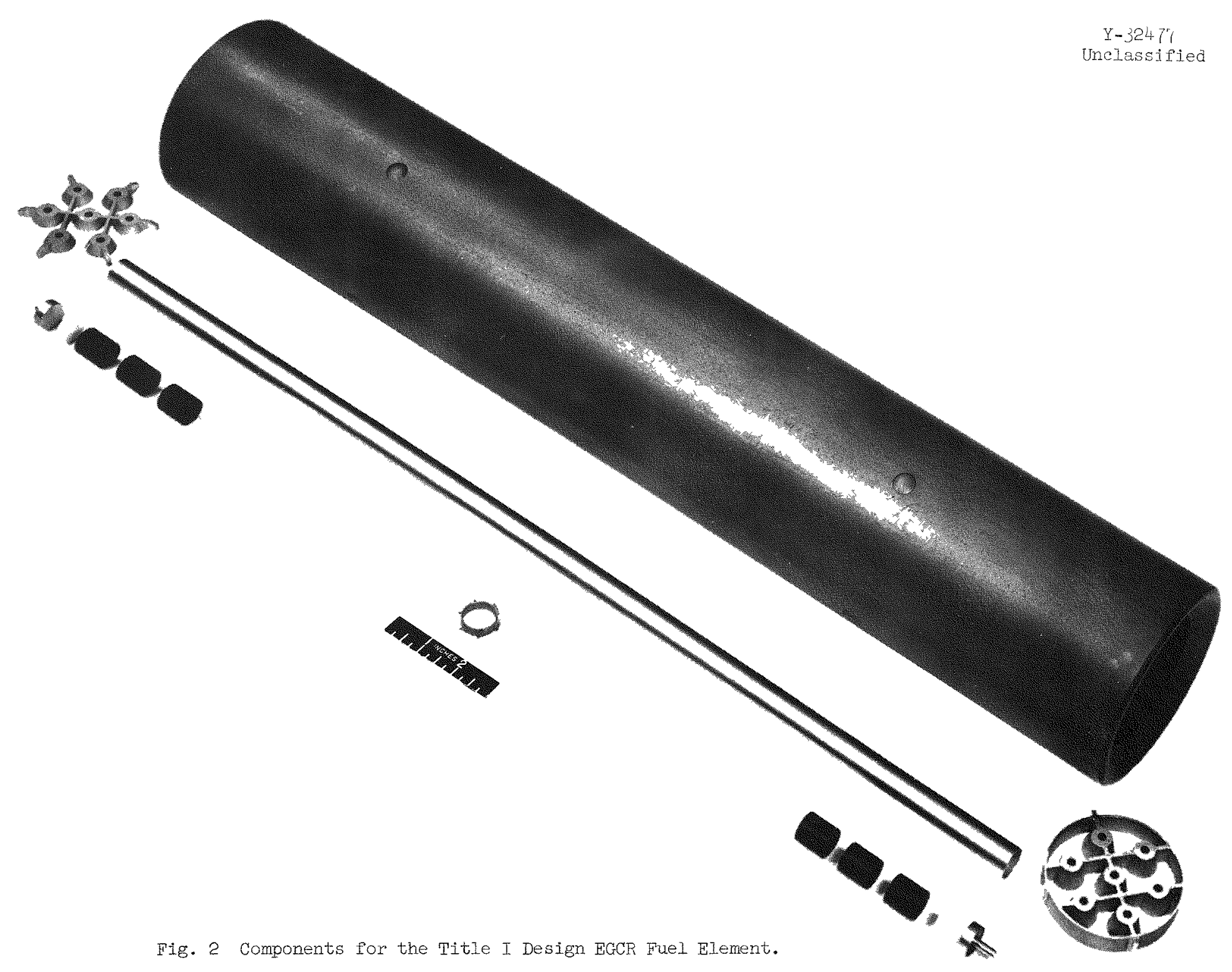


was used as a development step for the inspection techniques. Most of the component parts were procured in accordance with inspection requirements which had been established or developed at the time of component procurement. After receipt at the Oak Ridge National Laboratory (ORNL), the parts were completely reinspected. This served two purposes: (1) to establish a confidence level for the vendor inspection and (2) to determine the validity of the specific inspection details and make any necessary modifications. In addition, some new inspection techniques were developed which had not been utilized in the component procurement. Included in the inspection program were the fuel-capsule tubing, top and bottom end caps, midplane spacers, top and bottom spiders, the end closure welds, and the graphite sleeves. All of the material evaluation was conducted in the NDT Development Group Laboratory with the exception of the penetrant inspection on the tubing and the inspection of approximately one-half of the closure welds, both of which were conducted by the Inspection Engineering Department. Each of the inspection techniques which were used is discussed in this report.

\section{TUBING}

The most comprehensive nondestructive evaluation was conducted on the 0.710-in. i.d. x 0.020-in.-wall type 304 stainless steel tubing which is to be used as the fuel capsule cladding material. The techniques used for flaw detection were fluorescent penetrant, eddy-current, and pulse-echo ultrasonics. Air-gage and resonance-ultrasonic techniques were used for dimensional measurements.

\section{Penetrant}

The penetrant technique ${ }^{2}$ should detect any defects which are open to the outer surface. The materials which were chosen for the inspection were ZI-22 penetrant, ZE-3 emulsifier, and $\mathrm{ZP}-4$ developer. ${ }^{3}$ The technique included

\footnotetext{
2R. B. Oliver, G. M. Tolson, and A. Taboada, "The Use of Penetrants for Inspection of Small Diameter Tubing," Symposium on Nondestructive Tests in the Field of Nuclear Energy, ASTM STP 223, Philadelphia, Pa., 1950.

${ }^{3}$ Manufactured by the Magnaflux Corporation, Chicago, Illinois.
} 
precleaning, a penetrant soak for $30 \mathrm{~min}$, an emulsification time of $1-1 / 2$ min, a wash in a lukewarm-water spray, drying, 15 min development, and examination under a 100-w black-light source.

This technique was used on 600 of the 27.5-in. lengths. Any discontinuity was evaluated by physical removal to determine the depth. Those exceeding 0.0025 in. were considered cause for rejection of the tube. Eleven of the 600 pieces contained such defects and were rejected. These were primarily pit-like discontinuities.

\section{Eddy Currents}

The encircling-coil eddy-current technique ${ }^{4}$ was used on the tubing in accordance with Spec. No. RMIS-7. (ref 5) The only deviation from the specification was the reference standard which was used. Instead of the specified transverse-filed notch, a longitudinal-milled notch was used. A study is in progress to determine the best notch-production technique, and the results will be used in a revision of Spec. No. RMIS-7.

An unsuccessful attempt was made by the tubing manufacturer to inspect the finished tubing using the above specification. This failure was due to the multiplicity of indications which were larger than those from rejectable discontinuities but were not caused by a defective condition in the tube. It is felt that many of these indications are due to small dimensional variations produced during the straightening operation. The presence of this "hoise" (signals not associated with true defects) prevented a realistic eddy-current examination on the tubing and the eddy-current inspection requirement was waived for the manufacturer. However, it was demonstrated on 172 of the 600 pieces that a valid and realistic eddy-current test could be performed immediately after the final drawing operation and prior to the final anneal and straightening operation. The specification will be revised where necessary to permit the eddy-current inspection at this stage of the manufacture.

\footnotetext{
4 J. W. Allen, Eddy-Current Testing in Practice, ORNL-2655 (Apr. 16, 1959 ).

5"Procedure Specification for the Eddy-Current Inspection of Thin-Wall Austenitic Stainless Steel Tubing," Spec. No. RMIS-7, Appendix A of this report.
} 
The results of the eddy-current examination performed at ORNL on the tubing were essentially the same as those determined at the vendor's plant. only 13 of the 600 pieces could have been considered acceptable by strict conformance with the specification.

\section{Pulse-Echo UItrasonics}

The pulse-echo ultrasonic technique ${ }^{6}$ provided more detailed knowledge of the tubing quality. This inspection was not required of the vendor, nor is it anticipated that it will be a necessary part of future purchase specifications for this capsule tubing. It was used at ORNL to assist in establishing confidence levels in the other inspections and to assure the quality level of the tubing. This was particularly desirable since the eddycurrent test was not useable on this "noisy" tubing. Although modifications of existing techniques permitted an increase in inspection speed by a factor of 4, it was still slower and more expensive than an eddy-current examination. The defect rejection level was the same as for the penetrant tests, i.e., any discontinuity with a depth exceeding 0.0025 in. The largest indications which were noted were from a few inner-surface mandrel marks having depths of from 0.001 to 0.002 in.

\section{Air Gage}

The air-gage measurements determined the conformance of the tubing to the inside-diameter tolerance of $0.710_{-0.000}^{+0.002}$ in. Twenty-two of the 600 lengths were found to exceed the specified dimensions and were rejected. All of these were out-of-round on the tube ends, probably due to deformation during or after final cutting to length.

\section{Resonance Ultrasonics}

The resonance ultrasonic technique ${ }^{7}$ was used to measure the wallthickness variation in the tubing and to assure its acceptability in accordance with the specified dimensions of $0.020 \pm 0.002$ in. Most of the tubing

R. B. Oliver, R. W. Mcclung, and J.K. White, Immersed Ultrasonic Inspection of Pipe and Tubing, ORNL-2254 (Feb. 15, 1957).

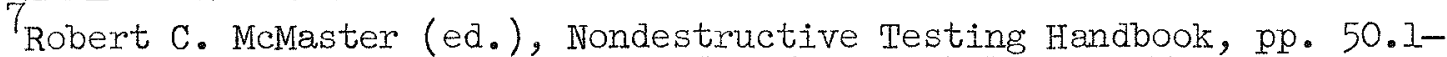
50.42, Vol. II, Section 50, The Ronald Press Company, New York, 1959. 
exhibited wall thicknesses near the high side of the tolerance. Twentyeight of the pieces were rejectable because of wall-thickness excursions which exceeded the tolerance. Only a portion of this tubing was examined at the vendor's plant by this technique. The results from their sampling indicated that approx $7 \%$ of the tubing failed to meet the wall-thickness tolerance as compared with the actual rejection at ORNL of less than 5\%.

\section{END CAPS}

The top and bottom end caps, shown in Fig. 3, are machined from bar stock. The only nondestructive test proposed for these parts is the postemulsification fluorescent-penetrant technique. 8 This should detect any defects which are open to the surface. The inspection materials chosen were the ZL-22 penetrant, ZZE-3 emilsifier, and ZP-4 developer. The technique included precleaning by vapor degreasing, a penetrant soak for 30 min, an emulsification time of $3 \mathrm{~min}$, wash in a lukewarm-water spray, drying, $15 \mathrm{~min}$ development, and examination under a 100-w black-light source. The emulsification time is one of the most critical portions of the technique. Shorter times were tried but machining marks on the concave section retained penetrant and presented strong indications under black-light examination. Evaluation demonstrated that these machining marks were less than 0.001 in. deep and were insignificant. Emulsification times longer than that specified would tend to remove the penetrant from significant defects. Four hundred seventy-five top end caps and five hundred seventy-four bottom end caps were examined by penetrants. All indications detected by this technique were evaluated by physical removal of the discontinuity. All of the discontinuities were removed within the dimensional tolerances and no rejection was made.

\section{MTDPLANE SPACERS}

The Title I design midplane spacer is shown in Fig. 4. The only nondestructive test proposed for the spacers is the post-emulsification

\footnotetext{
${ }^{8}$ Ibid., pp. 6.1-6.24, Vol.I, Section 6.
} 

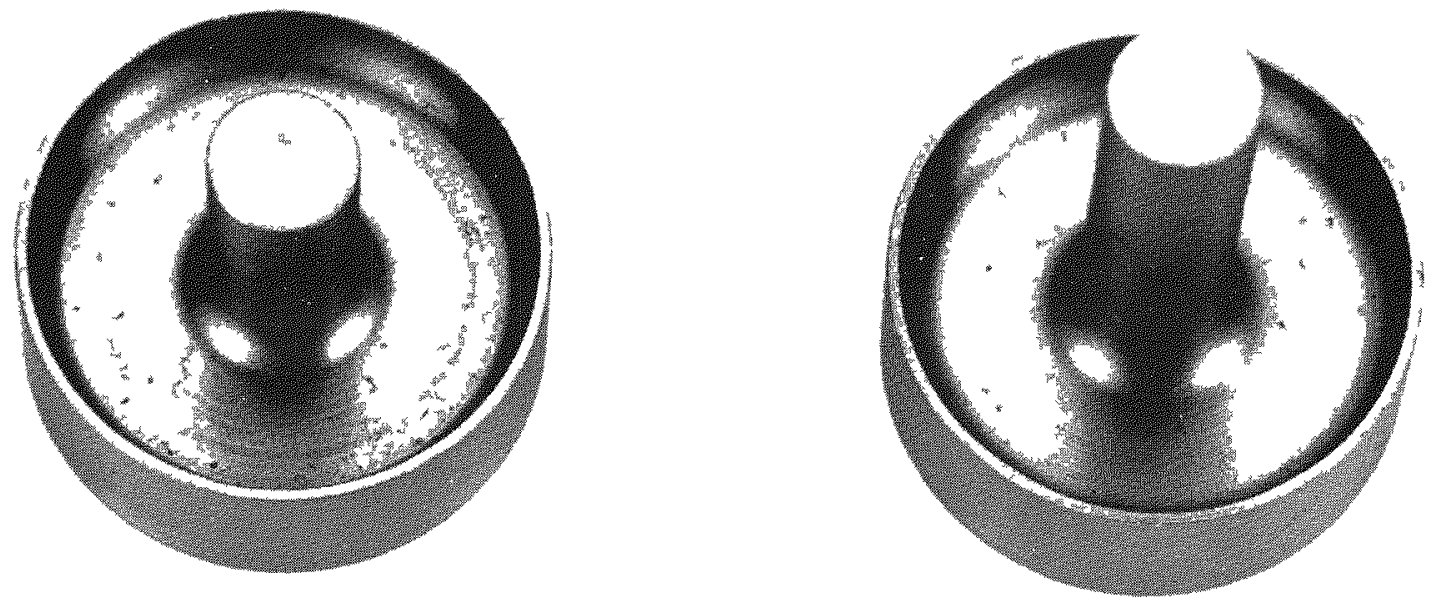

\subsection{IN IDIV | | | |}

Fig. 3 Top and Bottom Caps for the Fuel Capsule. 

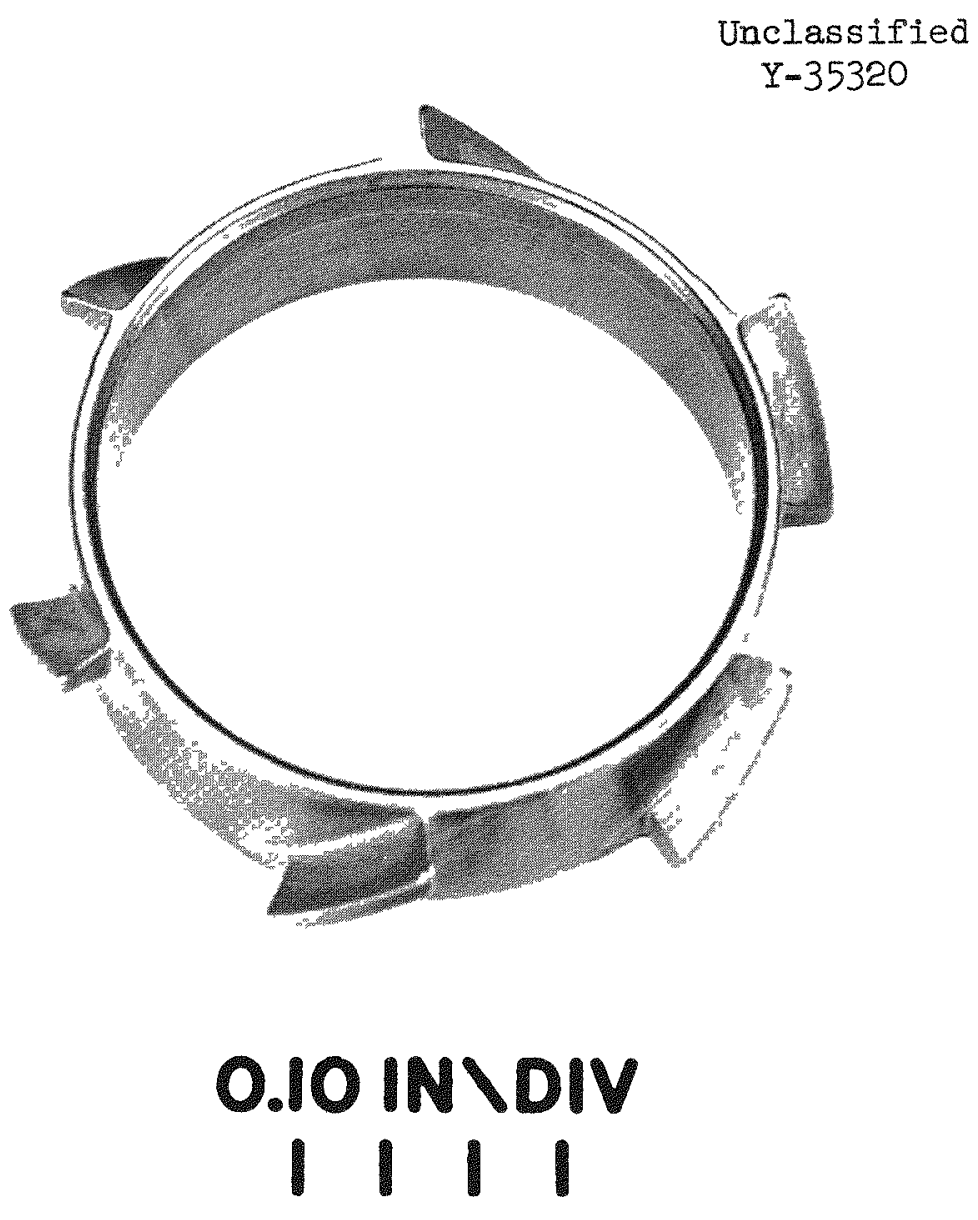

Fig. 4 Title I Design Midplane Spacer for the Fuel Capsule. 
fluorescent-penetrant technique. The technique which was established for the end caps proved to be optimum for the five hundred ninety-eight spacers. Machining marks around the fins precluded shorter emulsification times. Burrs which had not been removed from the fins after machining caused the greatest number of indications but were not considered to be sufficient reason for rejection. All other indications were evaluated by physical removal of the discontinuity and were removed within the dimensional tolerance with no rejection being made.

\section{SPIDERS}

The inspection methods of fluorescent penetrant and radiography were used for the nondestructive evaluation of the investment-cast top and bottom spiders (illustrated in Fig. 5). An attempt was made to use the post-emulsification fluorescent-penetrant technique which was utilized for the inspection of the end caps and spacers. However, the difficulty in removing this type of penetrant from the as-cast surface of these parts caused a residual background of fluorescence which prevented any valid examination. For this reason a slightly less sensitive, water-washable fluorescent penetrant was used which could be removed from the casting surface. The materials used were ZL-IA penetrant and ZP-4 developer. 9 The technique included precleaning by vapor degreasing, a penetrant soak for $30 \mathrm{~min}$, a wash in a lukewarm-water spray for $30 \mathrm{sec}$, drying, $15 \mathrm{~min}$. development, and examination under a 100-w black-light source. The wash time is one of the most critical portions of the technique. Shorter wash time may leave a residual fluorescent background on the specimen surface which would make examination difficult. Longer wash times may tend to remove the water-washable penetrant from defects.

Fifty-six of the bottom spiders and ninety-five of the top spiders were examined using the penetrant technique with only linear or crack-like indications being considered significant for this inspection. If the discontinuity could be removed within the dimensional tolerance, the spider was considered to be acceptable. Several discontinuities were detected

\footnotetext{
9 Manufactured by the Magnaflux Corporation, Chicago, Illinois.
} 
Unclassified

ORNL, Photo 48811

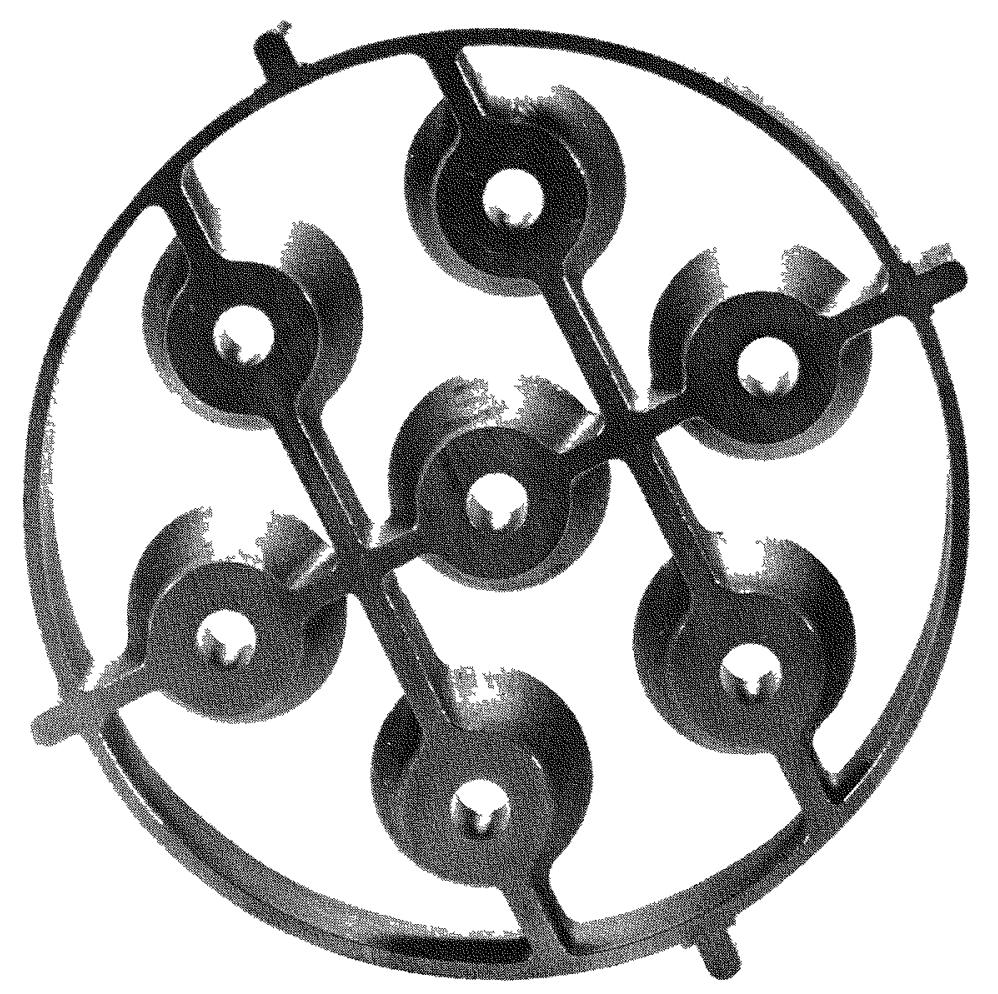

Top
Unclassified

ORNL Photo 48815

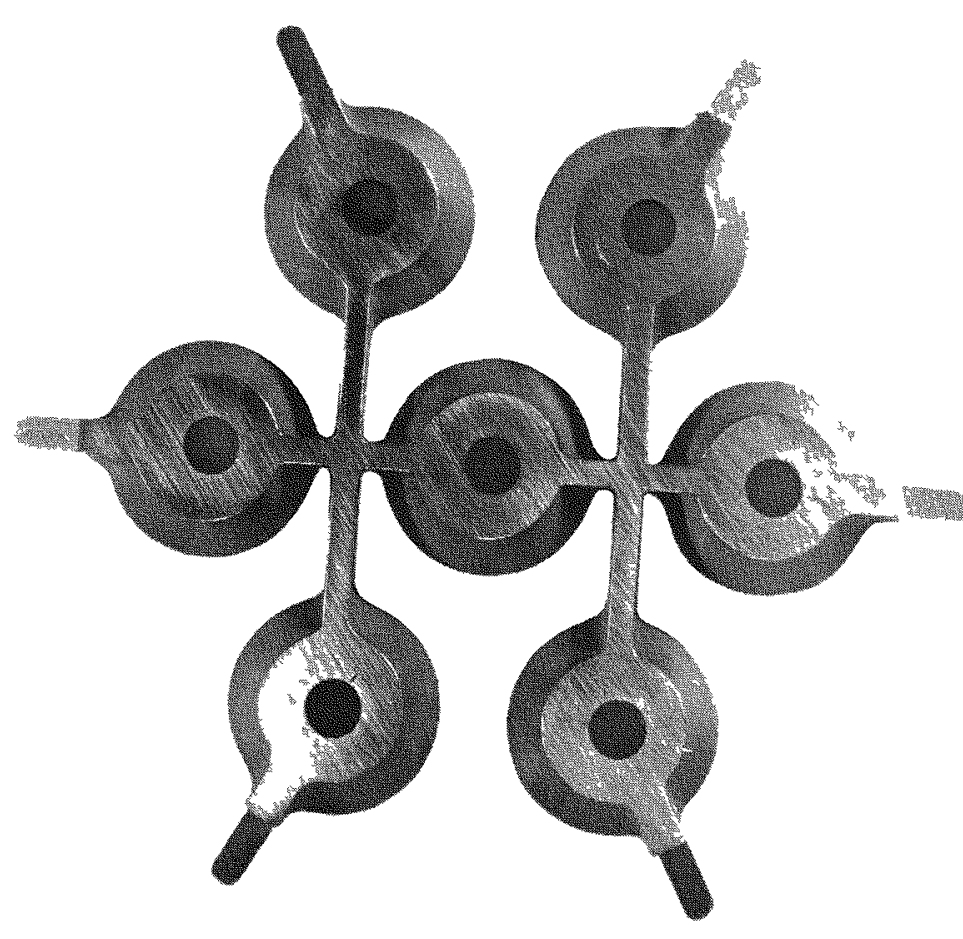

Bottom

Fig. 5 Title I Design Top and Bottom Spiders. 
and evaluated with two top spiders being rejected. One of these had been labeled as rejected at the manufacturer's plant because of a casting flaw in the outer ring. The second was rejected because of the crack across the rib adjacent to the center boss as shown in Fig. 6. Metallographic sectioning of this crack determined that it was about $1 / 16$ in. deep.

Acceptable radiographic techniques were established for both top and bottom spiders. Standard $2 \%$ sensitivity in a single exposure was readily achieved on all portions with the exception of the thin outer ring of the top spider. The scattered radiation superimposed on the image of the thin cross-sectional area reduced the sensitivity to about $4 \%$. A few areas of small porosity were detected and accepted as being nondetrimental. Fiftysix bottom spiders and ninety-five of the top spiders were radiographed with no rejection being made.

\section{CAPSULE CLOSURE WELDS}

The inspection techniques developed and applied to the fuel-capsule closure welds included helium leak testing, fluorescent penetrants, and radiography. Initially, each inspection was applied to the first closure weld before any further fabrication was accomplished on the capsule. However, because of the good quality of the welds and to avoid delays in the fabrication schedule, it was decided to examine both closure welds after loading of the capsule.

\section{Helium Leak Testing}

The helium leak test was conducted in accordance with Spec. No. RMIS-8 (ref 10) with one modification. This involved checking the instrument calibration for each inspection rather than an indefinite interval not to exceed eight hours. This change will be made an integral part of the written procedure. The reference-standard leak had a rate of $7 \times 10^{-9}$ std cc/sec. The procedure required the indication from the standard to be at least twice that of the background noise. Any through-leak in a capsule which produced an indication twice that of the background was considered to be rejectable.

10"Procedure Specification for Helium Leak Testing of Gas-Cooled Reactor Fuel Capsules," Spec. No. RMIS-8, Appendix B of this report. 
Unclassified

$Y-33758$

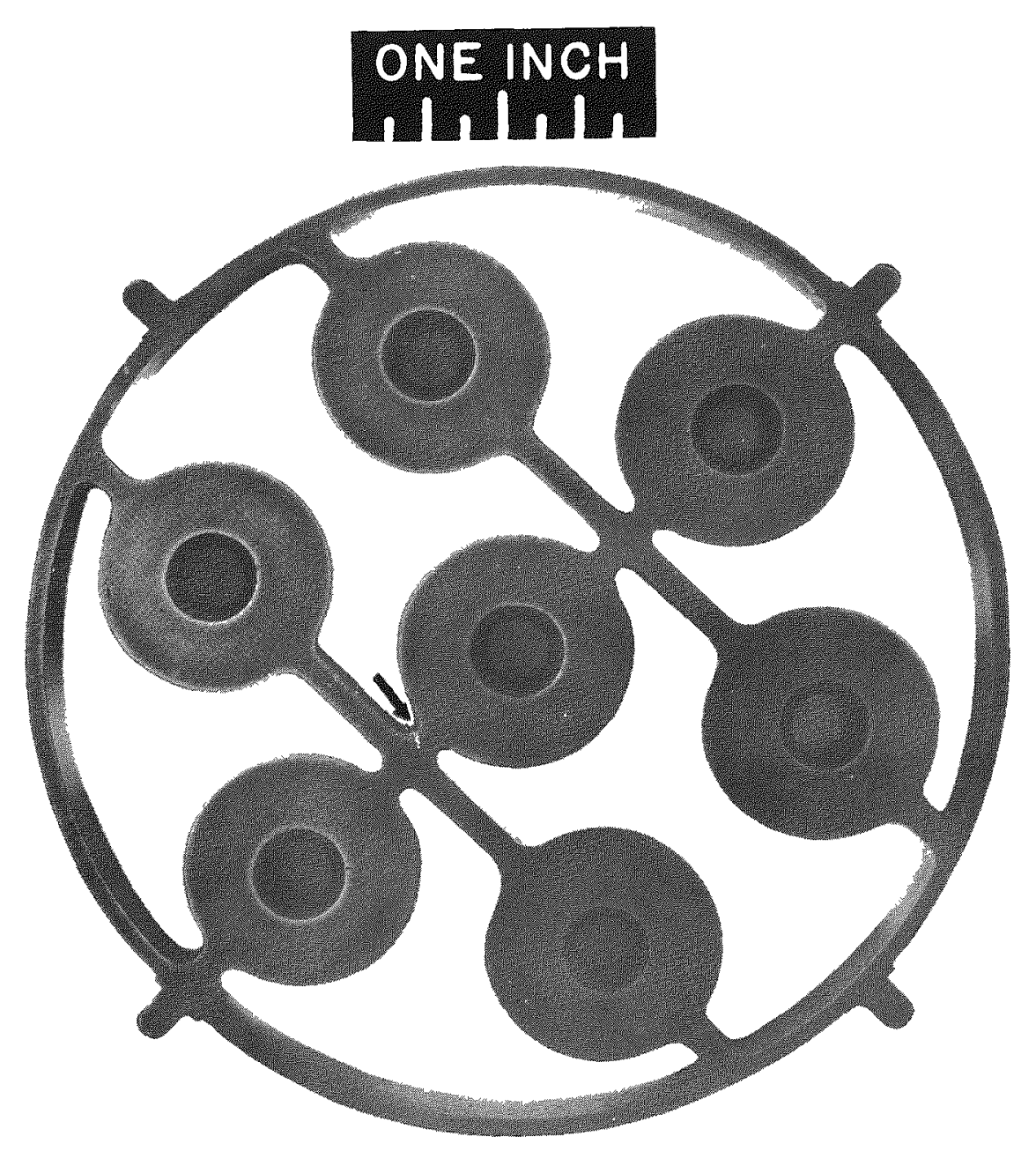

Fig. 6 Black-Iight Photograph of Crack in Top Spider. 
Two of the approx 350 capsules (700 welds) were found to present indications which were of rejectable size.

\section{Penetrant Inspection}

The fluorescent-penetrant technique was used to detect those discontinuities which extended to the outer surface but did not completely penetrate the weld. The materials used were the ZI-IA penetrant and the ZP-4 developer. The technique included precleaning by vapor degreasing, a penetrant soak for $30 \mathrm{~min}$, a wash in a lukewarm-water spray for about 15 sec, drying, 15 min development, and examination under a 100-w blacklight source. Similar to the inspection of the spiders, the wash time is one of the most critical portions of the technique. Every penetrant indication of a discontinuity was evaluated by physical removal of the flaw. Any flaw which exceeded a depth of 0.0025 in. was considered cause for rejection. No defects were found which exceeded this tolerance.

\section{Radiographic Inspection}

Radiographic inspection was accomplished to detect those subsurface voids which neither connected to the outer surface nor offered a through path for leakage from the interior of the capsule. The possible orientations of the radiation beam and film relative to the weld made the detection of cracks and lack of penetration somewhat impractical. However, it was accomplished to detect porosity and inclusions.

Two radiographic techniques were established and both were used to inspect the closure welds in an attempt to determine which was the optimum. The first technique is illustrated in Fig. 7. The weld is radiographed directly through the 0.200-in.-diam pin of the end cap. The type 304 stainless steel mask, which fits snugly around the cap configuration, increases the total thickness of the metal to 0.250 in. between the radiation source and the weld. The minimum detectable defect size is approx 0.004 to $0.006 \mathrm{in}$. as limited by the film and other considerations exclusive of the specimen thickness. This minimum size is still attainable through the 0.250-in. mask even though the available subject contrast is decreased. The principal advantage of the mask is that undercut and scatter from the 


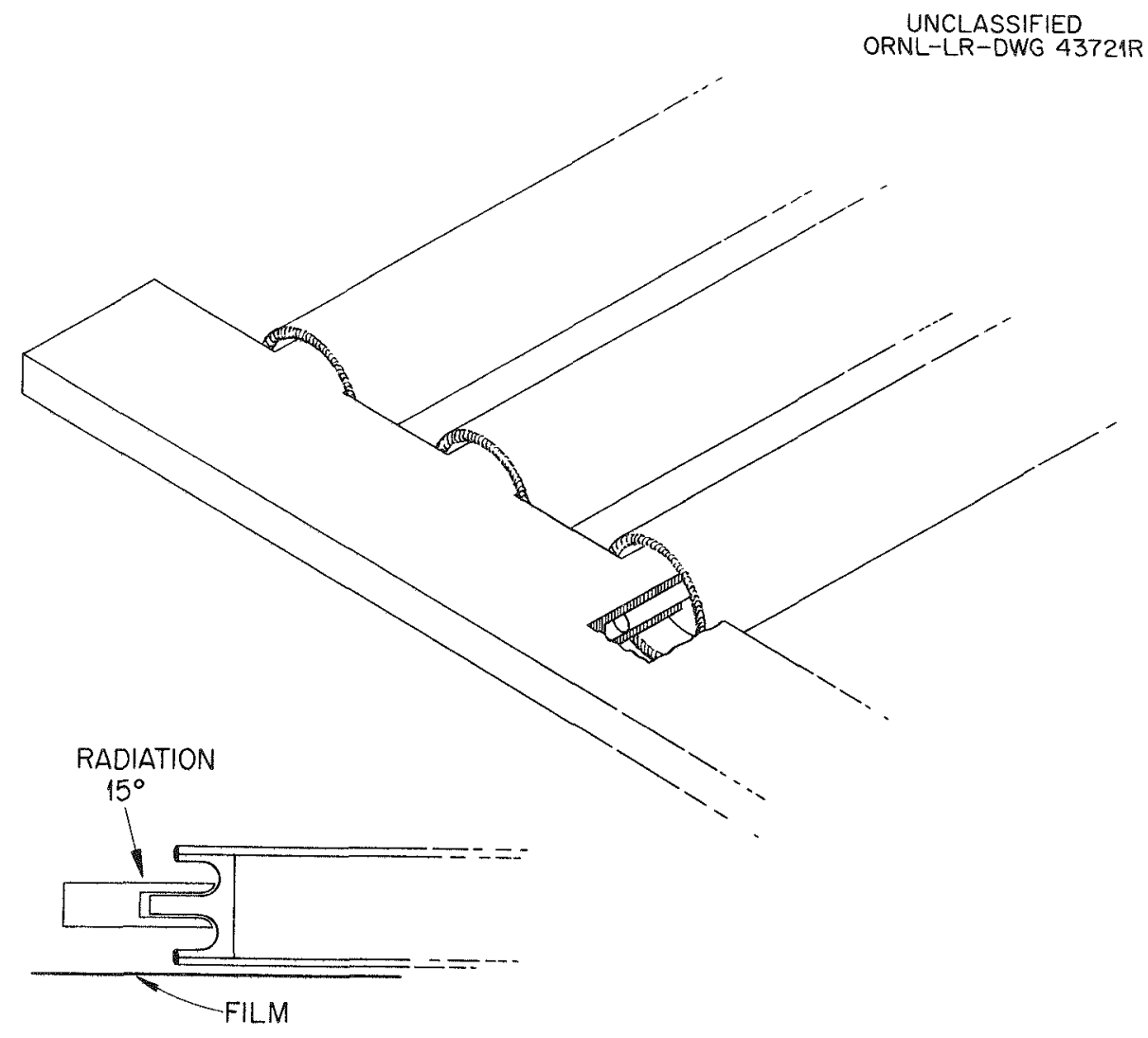

Fig. 7 Masking Technique for the Radiographic Inspection of EGCR Fuel Capsule Closure Welds. 
this technique. An alternate eddy-current technique which proved to be successful incorporates a small probe coil which is placed tangent to the sleeve surface. As the sleeve is rotated, the coil is advanced longitudinally at such a rate as to provide a helical scan along the surface with sufficient overlap to assure $100 \%$ inspection. This inspection is accomplished on both the outer and inner surfaces.

The reference discontinuity was a milled notch $0.100 \mathrm{in}$. deep. Any discontinuity in the inspected graphite sleeves which produced an indication greater than that from the reference notch was considered to be rejectable. Approximately fifty sleeves each from three manufacturers were examined by this technique with rejection rates varying from $34 \%$ for the product of one vendor to $92 \%$ for the poorest quality batch. Metallographic examination of selected discontinuities revealed the presence of cracks and porous, lowdensity areas on both inner and outer surfaces. Figure 9 shows the metallographic sections through a crack which extended for most of the sleeve length and the eddy-current indications which were obtained from the crack.

\section{CONCLUSIONS}

This pilot plant study on the nondestructive testing techniques for the EGCR fuel element was a vital portion of the inspection development program. Those techniques which had been tentatively proposed were evaluated and modified as necessary. Some of the inspection techniques were completely developed and evaluated during this program. The rather low rejection rate on the components which had received reasonable inspection, in accordance with ORNL requirements, indicates that properly controlled vendor inspection should be adequate to assure integrity. It is believed that technical data are now available for the preparation or modification of inspection specifications which will define the "proper control" on EGCR fuel element components and assemblies. Of course, changes in fuel element design may require minor modifications in some of the specific techniques. However, design changes made to date have not necessitated revisions in the inspection techniques. 


\section{4 \\ CURRENT SIGNAL TRACE OF SPIRAL SCAN ALONG SLEEVE}

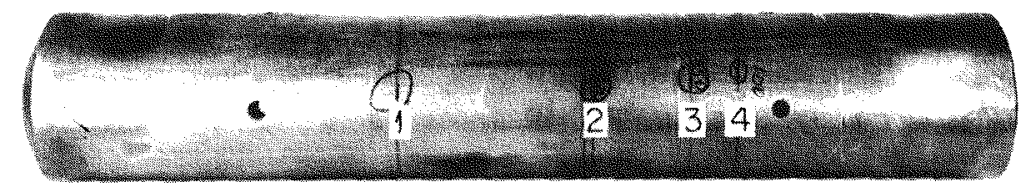

$$
\text { لسلسلسلسلس الس } 4
$$

EGCR GRAPHITE SLEEVE

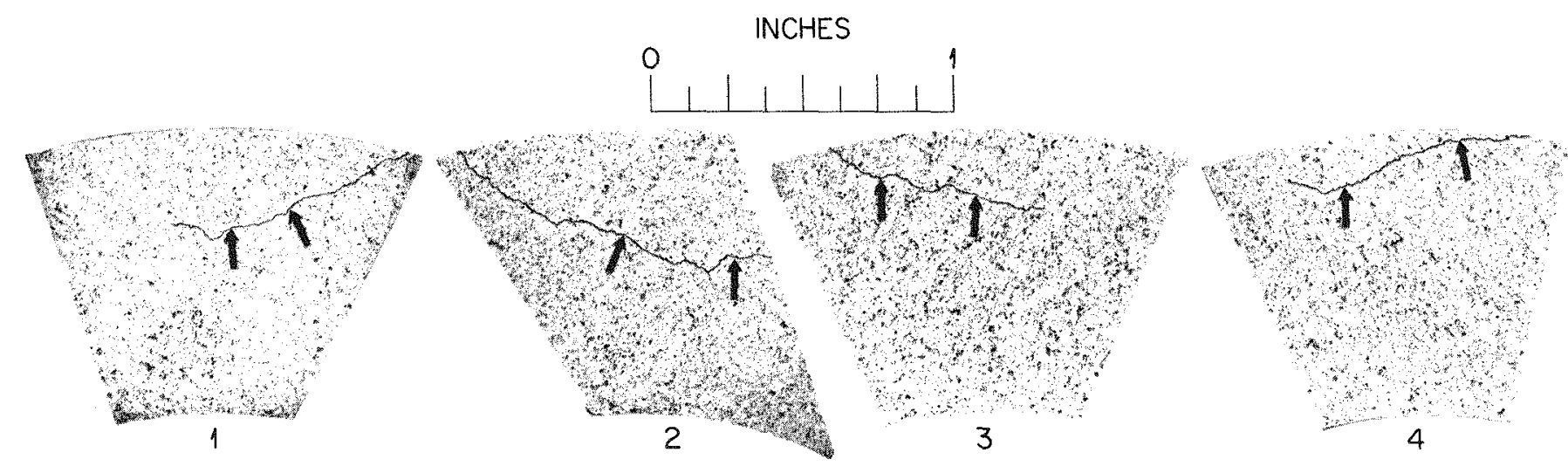

Fig. 9 Eddy-Current Inspection of EGCR Graphite Sleeve. (Photograph retouched to enhance cracking.) 
-

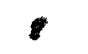

• 
APPENDIX A 
$$
\text { . }
$$ 
REACTOR MATERIAL SPECIFICATION

METALIURGY DIVISION

OAK RIDGE NATIONAL ILABORATORY

Union Carbide Wuclear Company

A Division of Union Carbide Corporation

Oak Ridge, Tennessee
Spec No. RMIS-7

Date: August 12, 1958

Revised: August 4, 1959

Page 1 of 4

\begin{tabular}{|c|c|}
\hline Subject: & $\begin{array}{l}\text { PROCEDURE SPECIFICATION FOR THE EDDY-CURRENT INSPECTION OF THIN- } \\
\text { WALI, AUSTENITIC STAINLESS STERL, TUBING }\end{array}$ \\
\hline
\end{tabular}

I. SCOPE: This document specifies the constitution of the approved eddycurrent procedure for the inspection of austenitic stainless steel tubing by the tubing manufacturer. This specification applies to the insection of tubing having nominal diameters between and including $1 / 4$ in. and 2 in. and wall thicknesses of $3 \%$ or Iess of the nominal tubing diameter.

II. TEECHICAL REQUIREMENTS:

A. The tubing shall be inspected in random lengths prior to cutting the tubing to the specified lengths. The uninspected ends (ref. Section IV-I of this specification) shall be removed before cutting the finished tubing to the specified lengths.

B. The inspection shall be accomplished by an inspector whose competence is certified by the vendor.

c. The inspection equipment used shall be suitable as described in Section III of this specification.

D. The defective portion of tubing classified "rejected" according to the provisions of Section $N-F$ of this specification shall be removed prior to cutting the tubing to final length. The defective section shall be marked in such a manner that it is clearly indicated that the defective section has been rejected by the eddy current inspection. A representative portion of these rejected sections, if any, shall be sent to the Metallurgy Division, Oak Ridge National Laboratory for examination; however, no rejected tubing having lengths of less than $2 \mathrm{ft}$ nor greater than $10 \mathrm{ft}$ shall be sent. This representative portion shall be considered a part of the specified amount on the purchase order, but shall not exceed $100 \mathrm{ft}$ or $10 \%$ of the specified amount on the purchase order, whichever is less.

E. The inspection procedure shall be in accordance with section IV of this specification or by an approved alternate. If an alternate procedure is desired, it shall be submitted to the Metallurgy Division, Oak Ridge National Laboratory for approval. 
REACTOR MATERIAI SPECIFICATION

METALIURGY DIVISION

OAK RIDGE NATIOIVAL IABORATORY
Spec No. RMCS-7

Date: August 12, 1958

Revised: August 4, 1959

Page 2 of 4

\section{Subject: PROCEDURE SPECIFICATION FOR THE EDDY-CURREIVI INSPECIION OF THIN- WALI AUSTENTTIC STATNI FSS STTEEL TUBTNG}

F. Standardization of the inspection shall be accomplished according to the provisions of Section $V$ of this specification or by an approved alternate. If an alternate standardization is desired, it shall be submitted to the Metallurgy Division, Oak Ridge National Laboratory for approval.

G. The tubing shall be inspected at the completion of the manufacturing process. Any deviation from this shall be submitted to the Metallurgy Division, Oak Ridge National Laboratory for approval.

III. INSPECIYION BQUIPMENT:

A. Inspection shall be accomplished using an encircling (feed through) coil system.

B. The mechanism used to drive the tubing through the coil system shall be capable of operating at a constant speed and shall be free from jerking and excessive vibration.

C. The sensitivity of the instrumentation shall be such that the provisions of section IV can be accomplished.

D. Signals from the inspection equipment sha]l be displayed in such a manner that the presence of a defect is clearly indicated.

IV. IISPECTION PROCEDURE:

A. A standard reference tube fabricated according to section $V$ of this specification shall be used to establish the sensitivity and response of the inspection system.

B. The tubing shall be driven through the coil system at a uniform rate of speed. The speed shall be in conformance with the capabilities of the inspection instrumentation and the operator to clearly detect the signal produced by the standard defect in the standard reference tube.

c. The equipment shall be adjusted in such a manner that a clear indication of the presence of the standard defect in the reference tube is obtained. 
REACTOR MAPERIAL SPEGIFICATION

METALIURGY DIVISION

OAK RIDGE NATIONAL IABORATORY
Spec No. RMIS-7

Date: August 12, 1958

Revised: August 4, 1959

Page 3 of 4

\section{Subject: PROCEDURE SPECIFICAFION FOR THE EDDY-CURREDVT INSPECTION OF THIN- WALL AUSTEMITIC STATMLESS STEETI TUBING}

D. The operating frequency of the instrument shall be chosen as low as possible, consistent with the reliable detection of the standard defect, but the frequency shall not exceed the maximum frequency calculated by the following formula:

$$
F_{\max }=\frac{36.5}{D^{2}} \mathrm{kc}
$$

$$
\text { where } \begin{aligned}
F= & \text { Frequency }(\mathrm{kc}) \\
D= & \text { Nominal Tubing Diameter } \\
& \text { (inches). }
\end{aligned}
$$

E. The standard reference tube shall be used periodically to check the performance of the inspection. If at any time the equipment fails to produce a clear indication of the presence of the standard defect, the equipment shall be readjusted to give a clear indication, and a.l1 tubing which has been inspected during the interim since the last satisfactory standardization shall be inspected again.

F. Any portion of the tubing which produces an indication as large or larger than the average indication produced by the standard notches in the standard reference tube as defined in Section $F D$ shall be classified as rejected.

G. If a phase detector is being utilized in the inspection equipment, the phase control shall be adjusted such that a phase shift of 10 degrees in either direction from the operational setting will not reduce the size of the indication from the standard defect more than $15 \%$.

H. The tubing shall be inspected by feeding it through the coil system in the direction wich produces the most sensitive inspection.

I. A test shall be devised by the vendor to determine the length of the uninspected ends of the tubing.

\section{STANDARD REFFREIVEE TUUBE:}

A. Standard reference tubes shall be fabricated fromtubing taken from the same heat and manufactured by the same processes as the tubing to be inspected.

B. Standard reference tubes shall be approximately 5 ft long. 
REACTOR MATERIAI, SPECIEICATION

METATUURGY DIVISTON

OAK RTDGE NATIONAL LABORATORY
Spec No. RMIS-7

Date: August 12, 1958

Revised: August 4, 1959

Page 4 of 4

\section{Subject: PROCEDURE SPECIFICATION FOR THE EDDY-CURRENTI INSPECTION OF THTN- WALI AUSTENITIC STAINLESS STERT TUBING}

c. Transverse notches shall be cut on the outside surface of the tube at approximately 3 in. intervals along the tube beginning 6 in. from each end of the tube. The notches shall be cut with a calibrated file notching tool containing $\mathrm{a} 1 / 4 \mathrm{in}$. round file and wich is capable of accurately controlling the depth of cut. The filed notch shall have a depth of $12.5 \%$ of the wall thickness. The axis of the file shell be held perpendicular to the axis of the tube and shall not traverse along the tube during the cutting operation. The axis of the file shall not be allowed to rotate about the axis of the tube nor shall the tube be allowed to rotate about its own axis during the cutting operation.

D. The standard reference tube shall be examined with the eddycurrent equipment. The average signal produced by the filed notches shall be determined and the depth of one of these notches which produces a signal equal to or greater than the average notch signal shall be accurately measured. If the depth of this notch is not greater than $12.5 \%$ of the wall thickness, the tube may be used as the standard reference tube for calibrating the eddycurrent equipment.

E. Any defect indication which may be present in the standard reference tube shall not be allowed to interfere with the identity or evaluation of the standard defects.

F. The standard reference tube shall be examined visually in the region of the standard defect to determine any damage to the tube as a result of the filing operation. The tubing shall be free of scores, dents, burrs, and other marks in the region of the standard defect.

G. Upon completion of the entire inspection, the standard reference tube shall be sent to the Metallurgy Division, Oak Ridge National Iaboratory. This tube shall be considered a part of the specified amount on the purchase order. 
APPENDIX B 
-

•

. 
REACTOR MATERIAL SPECIFICATION

METALIURGY DIVISION

OAK RIDGE NATIONAL IABORATORY

Union Carbide Nuclear Company

A Division of Union Carbide Corporation

Oak Ricige, Tennessee
Spec No. RMIS 8

Date: $\quad$ August 6, 1959

Revised: October 13, 1959

Page 1 of 4

Subject: PROCEDURE SPECIFICATION FOR HELIUM LEAK TTESTING OF GAS-COOLED REACTOR FUEL CAPSULES

I. SCOPE: This specification applies to the envelope method of helium leak testing the first closure weld before assembly and to the bell jar method of testing the assembled, helium-containing fuel capsules after the final closure weld has been accomplished.

II. REFERENCE: The manufacturer's operating manual for the particular instrument used in the inspection.

III. EQUIPMEIVI:

A. A mass spectrograph type, helium-sensitive instrument, similar to the Veeco-Type MS-9 or Consolidated Engineering Corporation Type 24-110, which includes the following as incorporated in the instrument or as additions or modifications:

1. A cold trap (Iiquid nitrogen or liquid air).

2. A helium leak source of $7 \times 10^{-9} \mathrm{std} \mathrm{cc} / \mathrm{sec}$.

3. An external or auxiliary roughing vacuum pump connected to the instrument manifold and to the specimen or test chamber through a vacuum valve.

4. A throttling or modulating valve between the instrument manifold and the instrument.

B. A low pressure supply of helium with a nozzle less than $1 / 16$ in. in diameter for use in checking for leak-tight connections.

C. One or more leak-tight chambers, each of which is capable of accommodating a fuel capsule for the final closure weld inspection and having no less than $3 / 8$ in. diametral clearance between the fuel capsule and the wall of the chamber.

D. An envelope capable of surrounding the capsule with an atmosphere of helium for the inspection of the first closure weld.

IV. TECHNICAL REQUIREMEINTS:

A. The instrument sensitivity shall be such that the stable signal from the standard leak, as determined in section $\mathrm{V}-\mathrm{C}-1$ \&2 of this specification, is at least two times as large as the signals produced by background noise. 
REACTOR MATERIAL SPECIFICATION

METAIUURGY DIVISION

OAK RIDGE NATIONAL LABORATORY
Spec No. RMIS 8

Date: August 6, 1959

Revised: October 13, 1959

Page 2 of 4

\section{Subject: PROCEDURE SPECIFICAIION FOR HELIUM LEAK TESTING OF GAS-COOLED} REACTOR FUEI CAPSULFS

B. The inspection shall be accomplished by an inspector whose competence is certified by the agency inspecting the fuel capsules.

C. The inspection chamber used in the bell jar inspection technique shall be thoroughly purged with a suitable gas after each inspection to insure the smallest possible helium background.

D. The inspection shall be performed in a force-ventilated location to facilitate the removal of any helium background.

E. The connecting lines between the test chamber and the instrument manifold shall be as short as is practical and should have a minimum inside diameter of $1 / 2$ in. All connections shall be leak-tight.

F. Care shall be exercised to avoid plugging leaks with any sealant prior to attempted detection with helium.

G. All assembled fuel capsules shall be either helium leak tested within 24 hours after the final closure weld is completed or stored in a helium atmosphere until such time as they can be helium leak tested. If a fuel capsule is to be retested or if the testing procedure is interrupted, as in Sections $V-A, V-F$, and $V-G$, the capsule shall be stored in a helium atmosphere until such time as testing can be completed. No assembled fuel capsule shall be allowed to remain in a non-helium atmosphere for more than a total of 48 hours between the time of its assembly and the completion of helium leak testing.

V. TESTING PROCEDURE:

A. The performance of the leak detector equipment shall be verified periodically (at least once each $8 \mathrm{hr}$. shift). If at any time this equipment fails to function properly as described in the manufacturer's operating manual and/or if the sensitivity as determined in section V-C of this specification decreases below the minimum level prescribed in Section IV-A the equipment shall be readjusted to function properly and recalibrated, and all fuel capsules which have been inspected during the interim since the last satisfactory performance verification of the equipment shall be inspected again. 
REACTOR MATERIAL SPECIFICATION

METALIURGY DIVISTON

OAK RIDGE NATIONAI ILABORATORY
Spec No. RMTS 8

Date: $\quad$ August 6, 1959

Revised: October 13, 1959

Page 3 of 4

Subject: PROCEDURE SPECIFICATION FOR HELIUM LEAK TESTING OF GAS-COOLED REACTOR FUEL CAPSULES

B. The closure welds shall be inspected as follows:

1. The initial closure weld shall be inspected by connecting the open end of the capsule tubing to the manifold of the leak detector and by placing the capsule tubing in an envelope of helium at atmospheric pressure. The search for leaks shall be made as prescribed in the instrument manufacturer's operating manual.

2. The assembled, helium-containing fuel capsules shall be inspected after the final closure weld has been accomplished by placing the fuel capsule in the inspection chamber, evacuating the chamber, and searching for helium leaks as prescribed in the instrument manufacturer's operating manual.

C. The instrument shall be calibrated as follows:

1. Envelope method.

The standard leak source $\left(7 \times 10^{-9} \mathrm{std} \mathrm{cc} / \mathrm{sec}\right)$ shall be connected to the manifold. The time which is required to produce a signal at least two times as large as the background noise shall be measured. This measurement shall be accomplished while examining a 100\% sample from the capsule tubing and with all valves between the capsule and the helium-sensing device completely open. This portion of the calibration shall be continued until the signal from the standard leak reaches a stable amplitude and manifold pressure shall be measured at this point.

2. Bell jar method.

The standard leak source $\left(7 \times 10^{-9} \mathrm{std} \mathrm{cc} / \mathrm{sec}\right)$ shall be connected to one end of the test chamber. The opposite end of the test chamber shall be connected to the manifold and the time which is required to produce a signal two times as large as the background noise shall be measured. This measurement shall be accomplished while examining a 100\% sample from the test chamber and with all valves between the standard leak source and the helium-sensing device completely open. This portion of the calibration shall be continued until the signal from the standard leak reaches a stable amplitude. The signal amplitude and manifold pressure shall be measured at this point. 
REACTOR MATERIAI, SPECIFICATION

METAILURGY DIVISION

OAK RIDGE NATIONAL ILABORATORY
Spec No. RMIS 8

Date: $\quad$ August 6, 1959

Revised: October 13, 1959 Page 4 of 4

Subject: PROCEDURE SPECIFICATION FOR HELIUM LEAK TESTING OF GAS-COOLED REACTOR FUET CAPSULES

D. The inspection shall be made taking a 100\% sample from either the interior of the capsule tubing or the test chamber depending upon which of the two methods is used. All valves between the capsule and the helium-sensing device shall be completely open and the time of inspection shall be no less than one minute and at least twice as long as that time (determined in section V-C of this specification for that particular method) required for the standard leak to produce a signal two times as large as the background noise.

E. The manifold pressure at wich the inspection is made shall be the same as the pressure at which the instrument is calibrated as measured in section $V-C$ of this specification for the particular method used.

F. Excessive pump-down time shall be indicative of an external leak. The leak shall be located and corrected before further testing is accomplished.

G. During the inspection any signal which produces an indication two times as large as the background noise level shall be indicative of a through path or leak in the capsule being inspected and that fuel capsule shall be rejected. If more thar one assembled fuel capsule is being inspected at the time a leak is detected, the capsules shall be inspected again such that the leaking capsule or capsules are identified and rejected.

H. All rejected, assembled, helium-containing fuel capsules shall be disassembled. Any salvable parts of the rejected fuel capsules may be reused in the assembly of other capsules.

I. Any rejected first closure weld may be recycled through the welding process unless there are obvious defects which would not be corrected by such a recycle. If a rejected first closure weld is rewelded, any inspection which may have been accomplished between the time of the first welding and the rejection by helium leak testing shall be repeated. 
REACTOR MATERIAL SPECIFICATION

METALLURGY DIVISION

OAK RIDGE NATIONAL LABORATORY
Spec No. RMIS 8

Date: August 6, 1959

Revised: October 13, 1959

Page 4 of 4

Subject: PROCEDURE SPECIFICATION FOR HELIUM LEAK TESTING OF GAS-COOLED REACTOR FUEL CAPSULES

D. The inspection shall be made taking a 100\% sample from either the interior of the capsule tubing or the test chamber depending upon which of the two methods is used. All valves between the capsule and the helium-sensing device shall be completely open and the time of inspection shall be no less than one minute and at least twice as long as that time (determined in Section V-C of this specification for that particular method) required for the standard leak to produce a signal two times as large as the background noise.

E. The manifold pressure at which the inspection is made shall be the same as the pressure at which the instrument is calibrated as measured in section V-C of this specification for the particular method used.

F. Excessive pump-down time shall be indicative of an external leak. The leak shall be located and corrected before further testing is accomplished.

G. During the inspection any signal which produces an indication two times as large as the background noise level shall be indicative of a through path or leak in the capsule being inspected and that fuel capsule shall be rejected. If more thar one assembled fuel capsule is being inspected at the time a leak is detected, the capsules shall be inspected again such that the leaking capsule or capsules are identified and rejected.

H. All rejected, assembled, helium-containing fuel capsules shall be disassembled. Any salvable parts of the rejected fuel capsules may be reused in the assembly of other capsules.

I. Any rejected first closure weld may be recycled through the welding process unless there are obvious defects which would not be corrected by such a recycle. If a rejected first closure weld is rewelded, any inspection which may have been accomplished between the time of the first welding and the rejection by helium leak testing shall be repeated. 


\author{
ORNL-3059 \\ Metals, Ceramics, and Materials \\ TID-4500 ( 16 th ed.)
}

\title{
INIERNAL DISTRIBUTION
}

1. C. E. Center

2. Biology Iibrary

3. Health Physics Library

4. Metallurgy Library

5-6. Central Research Iibrary

7. ORNL - Y-12 Technical Library, Document Reference Section

8-12. Laboratory Records

13. Iaboratory Records, R.C.

14. G. M. Adamson, Jr.

15. R. J. Beaver

16. M. Bender

17. D. S. Billington

18. A. I. Boch

19. E. G. BohImann

20. B. S. Borie

21. C. J. Borkowski

22. R. B. Briggs

23. N. A. Brown

24. J. V. Cathcart

25. R. A. Charpie

26. G. W. Clark

27. R. E. Clausing

28. R. S. Cockreham

29. J. H. Coobs

30. F. I. Culier

31. J. E. Cunningham

32. J. H. DeVan

33. D. A. Douglas, Jr.

34. I. B. Emlet $(\mathrm{K}-25)$

35. A. P. Fraas

36. J. H. Frye, Jr.

37. A. E. Goldman

38. R. J. Gray

39. B. I. Greenstreet

40. W. R. Grimes

41. J. P. Hammond

42. W. O. Harms

43. T. Hikido

44-148. M. R. HilI

49. E. E. Hoffman

50. A. Hollaender

51. A. S. Householder

52. H. Inouye

53. C. P. Keim
54. M. T. Kelley

55. R. B. Korsmeyer

56. J. A. Lane

57. S. C. Lind

58. R. S. Livingston

59. H. G. MacPherson

60. W. D. Manly

61. W. R. Martin

62-66. R. W. McClung

67. C. J. McHargue

68. A. J. Miller

69. E. C. Miller

70. J. G. Morgan

71. K. Z. Morgan

72. J. P. Murray (Y-I2)

73. M. I. Nelson

74. P. Patriarca

75. A. M. Perry

76. D. Phillips

77. P. M. Reyling

78. G. Samuels

79. H. W. Savage

80. A. W. Savolainen

81. J. I. Scott

82. H. E. Seagren

83. E. D. Shipley

84. O. Sisman

85. M. J. Skinner

86. G. M. Slaughter

87. C. 0. Smith

88. E. E. Stansbury

89. E. Storto

90. J. A. Swartout

91. E. H. Taylor

92. W. C. Thurber

93. G. M. Tolson

94. D. B. Trauger

95. A. M. Weinberg

96. J. R. Weir, Jr.

97. E. A. Wick

98. C. E. Winters

99. J. H. Koenig (consultant)

100. C.S. Smith (consultant)

101. R. Smoluckowski (consultant)

102. H. A. Wilhelm (consultant) 
EXTERNAI DISTRIBUTION

103. J. L. Gregg, Cornell University

104. J. M. Simmons, DRD, AEC, Washington, D.C.

105. Division of Research and Development, AEC, ORO

106-607. Given distribution as shown in TID-4500 (16th ed.) under Metals, Ceramics, and Materials 